\title{
Cerebral venous thrombosis requiring invasive treatment for elevated intracranial pressure in women with combined hormonal contraceptive intake: risk factors, anatomical distribution, and clinical presentation
}

\author{
*Michel Roethlisberger, MD,1 Lara Gut, MD, ${ }^{1}$ Daniel Walter Zumofen, MD, ${ }^{1,2}$ Urs Fisch, MD, PhD, ${ }^{3}$ \\ Oliver Boss, MD, ${ }^{1}$ Nicolai Maldaner, MD, ${ }^{4}$ Davide Marco Croci, MD, ${ }^{1}$ Ethan Taub, MD, ${ }^{1}$ \\ Natascia Corti, MD, ${ }^{4}$ Jan-Karl Burkhardt, MD, ${ }^{5,6}$ Raphael Guzman, MD, ${ }^{1}$ Oliver Bozinov, MD, ${ }^{6}$ and \\ Luigi Mariani, MD'

\begin{abstract}
Departments of ${ }^{1}$ Neurosurgery and ${ }^{3}$ Neurology, and ${ }^{2}$ Division of Diagnostic and Interventional Neuroradiology, Department of Radiology, University Hospital Basel and University of Basel, Basel; Departments of ${ }^{4} \mathrm{Clinical}$ Pharmacology and ${ }^{6}$ Neurosurgery, University Hospital Zürich and University of Zürich, Zürich, Switzerland; and ${ }^{5}$ Department of Neurological Surgery, NYU School of Medicine, NYU Langone Medical Center, New York, New York
\end{abstract}

OBJECTIVE Women taking combined hormonal contraceptives ( $\mathrm{CHCs}$ ) are generally considered to be at low risk for cerebral venous thrombosis (CVT). When it does occur, however, intensive care and neurosurgical management may, in rare cases, be needed for the control of elevated intracranial pressure (ICP). The use of nonsurgical strategies such as barbiturate coma and induced hypothermia has never been reported in this context. The objective of this study is to determine predictive factors for invasive or surgical ICP treatment and the potential complications of nonsurgical strategies in this population.

METHODS The authors conducted a 2-center, retrospective chart review of 168 cases of CVT in women between 2000 and 2012. Eligible patients were classified as having had a mild or a severe clinical course, the latter category including all patients who underwent invasive or surgical ICP treatment and all who had an unfavorable outcome (modified Rankin Scale score $\geq 3$ or Glasgow Outcome Scale score $\leq 3$ ). The Mann-Whitney U-test was used for continuous parameters and Fisher's exact test for categorical parameters, and odds ratios were calculated with statistical significance set at $p \leq 0.05$.

RESULTS Of the 168 patients, 57 (age range 16-49 years) were determined to be eligible for the study. Six patients $(10.5 \%)$ required invasive or surgical ICP treatment. Three patients $(5.3 \%)$ developed refractory ICP > $30 \mathrm{~mm} \mathrm{Hg} \mathrm{de-}$ spite early surgical decompression; 2 of them (3.5\%) were treated with barbiturate coma and induced hypothermia, with documented infectious, thromboembolic, and hemorrhagic complications. Coma on admission, thrombosis of the deep venous system with consecutive hydrocephalus, intraventricular hemorrhage, and hemorrhagic venous infarction were associated with a higher frequency of surgical intervention. Coma, quadriparesis on admission, and hydrocephalus were more commonly seen among women with unfavorable outcomes. Thrombosis of the transverse sinus was less common in patients with an unfavorable outcome, with similar distribution in patients needing invasive or surgical ICP treatment.

CONCLUSIONS The need for invasive or surgical ICP treatment in women taking CHCs who have CVT is partly predictable on the basis of the clinical and radiological findings on admission. The use of nonsurgical treatments for refractory ICP, such as barbiturate coma and induced hypothermia, is associated with systemic infectious and hematological complications and may worsen morbidity in this patient population. The significance of these factors should be studied in larger multicenter cohorts.

https://thejns.org/doi/abs/10.3171/2018.4.FOCUS1891

KEYWORDS cerebral venous thrombosis; combined hormonal contraceptive intake; intracranial pressure; decompressive surgery; barbiturate coma; induced hypothermia

ABBREVIATIONS CHC = combined hormonal contraceptive; CVT = cerebral venous thrombosis; GCS = Glasgow Coma Scale; GOS = Glasgow Outcome Scale; ICP = intracranial pressure; $\mathrm{mRS}=$ modified Rankin Scale.

SUBMITTED February 28, 2018. ACCEPTED April 4, 2018.

INCLUDE WHEN CITING DOI: 10.3171/2018.4.FOCUS1891.

* M.R. and L.G. contributed equally to this study. 
$\mathrm{C}$ EREBRAL venous thrombosis (CVT) is a rare event, with an incidence of 5 per million per year, and accounts for $0.5 \%$ to $1 \%$ of all strokes. ${ }^{5,28} \mathrm{CVT}$ is 3 times more common in women than in men and is also more common in patients under 40 years of age..$^{13}$ Recent studies have shown that the overall incidence of CVT may be even higher than previously thought because its clinical features may be subtle; population-based studies are pending. ${ }^{28}$

The intake of combined hormonal contraceptives (CHCs) increases the risk of CVT by a factor of 7.6 and is very common. ${ }^{1}$ Besides obesity, which has recently been shown to double the risk of CVT in combination with $\mathrm{CHC}$ intake, ${ }^{33}$ a variety of inherited and acquired risk factors are described in the literature. ${ }^{13}$ Cigarette smoking combined with $\mathrm{CHC}$ intake and a positive family history or personal history of a prior thrombotic event are known to be important risk factors for deep vein thrombosis and pulmonary thromboembolism ${ }^{3,29}$ but have not been shown to be so for CVT. ${ }^{10}$

CVT can be successfully treated with anticoagulation (e.g., with intravenous or subcutaneous heparin) in most cases. ${ }^{28}$ The outcome of CVT can be severe or fatal, however: the acute 30 -day mortality is $3.4 \%$, and the rate of dependency on nursing care at the time of discharge is $14.6 \% .^{8,13}$ A small percentage of patients sustain clinical complications necessitating intensive care management or neurosurgical interventions. ${ }^{15,18,28}$ In general, invasive or surgical intracranial pressure (ICP) treatment is rarely needed. ${ }^{14,15,18}$ Endovascular treatment options using modern approaches are emerging within this context and seem to be safe and effective when conventional management fails. ${ }^{4,20,24,25,27}$ Retrospective and prospective observational studies suggest that early decompressive surgery prevents death and does not result in an excess of severe disability, ${ }^{14,34}$ but specific data on additional medical treatment in CVT remain scarce..$^{911}$ In particular, the use of barbiturate coma and induced hypothermia in patients with refractory ICP due to CVT has not been described in the literature.

The primary objective of this retrospective study was to determine risk factors and predictive factors for surgical interventions and unfavorable outcome in a homogeneous group of nonpregnant women who sustained an unprovoked CVT with concurrent or recent $\mathrm{CHC}$ intake. The secondary objective was to determine the complications of nonsurgical ICP treatment options (barbiturate coma and induced hypothermia) in the subgroup of patients with refractory $\mathrm{ICP}$.

\section{Methods \\ Study Centers}

This study was performed in 2 large tertiary care university hospitals (Basel and Zurich). The local ethics committees approved the study in December 2014 (Basel) and October 2015 (Zürich). Both local ethics committees waived the need for obtaining written informed consent. This study is a retrospective analysis of preexisting data without intervention and therefore does not require clinical trial registration. One author (L.G.) conducted retrospective patient chart review for both centers.

\section{Inclusion and Exclusion Criteria}

Female patients with diagnosed cerebral venous thrombosis (CVT) of the dural sinuses, involvement of the deep venous system (DCVT), cortical venous thrombosis, or with thrombosis of the jugular system based on the International Statistical Classification of Diseases and Related Health Problems, as well as documented intake of CHCs were included. The criteria for exclusion were 1) missing information about the diagnosis or CHC intake and 2) the documented presence of CVT-provoking factors, including pregnancy, infection, and previous surgery (Fig. 1).

\section{Study Variables}

Treatment information included conservative management, intensive care, invasive or surgical ICP treatment, and barbiturate coma and/or induced hypothermia. Outcome values at discharge were scores on the modified Rankin Scale (mRS) ${ }^{12}$ and Glasgow Outcome Scale (GOS), ${ }^{17,30}$ dichotomized into favorable and unfavorable categories (favorable: $\mathrm{mRS}$ score $\leq 2$ or GOS score $\geq$ 4 points; unfavorable: $\mathrm{mRS}$ score $\geq 3$ or GOS score $\leq$ 3 points). On the basis of this information, the clinical course was designated as "mild" if it involved conservative treatment on the ward or only short-term sedation for seizures in an intensive care unit, no need for invasive or surgical ICP treatment, and a favorable outcome on discharge. In all other cases, the clinical course was designated as "severe." Based on computed tomography (CT) and magnetic resonance imaging (MRI) with venographic studies (CT venography [CTV] and MR venography [MRV]), 5 radiological variables were documented for each patient: the type and extent of thrombosis, hemorrhage, edema, venous infarction, and hydrocephalus. Five clinical variables were documented as well: Increased intracranial pressure (ICP) was defined as a pressure greater than $15 \mathrm{~mm} \mathrm{Hg}$ by lumbar puncture or evident clinical signs of intracranial hypertension (e.g., a combination of headaches, nausea, vomiting, altered consciousness, papilledema). The clinical signs assessed on admission and discharge that were considered were the Glasgow Coma Scale (GCS) score, new focal neurological deficits, cranial nerve deficits, and seizures (Fig. 1).

\section{Statistical Analysis}

Continuous variables are reported as the mean or median and range, categorical variables as absolute numbers and percentages. Comparisons between groups were performed with the Mann-Whitney U-test for continuous parameters and Fisher's exact test for categorical parameters. Odds ratios and corresponding $\mathrm{p}$ values were calculated without a multivariate model because of the small sample size. Statistical significance was set at $\mathrm{p} \leq 0.05$.

\section{Results}

The initial screening identified 168 patients in both centers within a time period of 12 years from 2000 to 2012 . A total of 111 did not meet the inclusion criteria because of male sex; having hard risk factors, including pregnancy, previous surgery, or infection; or missing information re- 


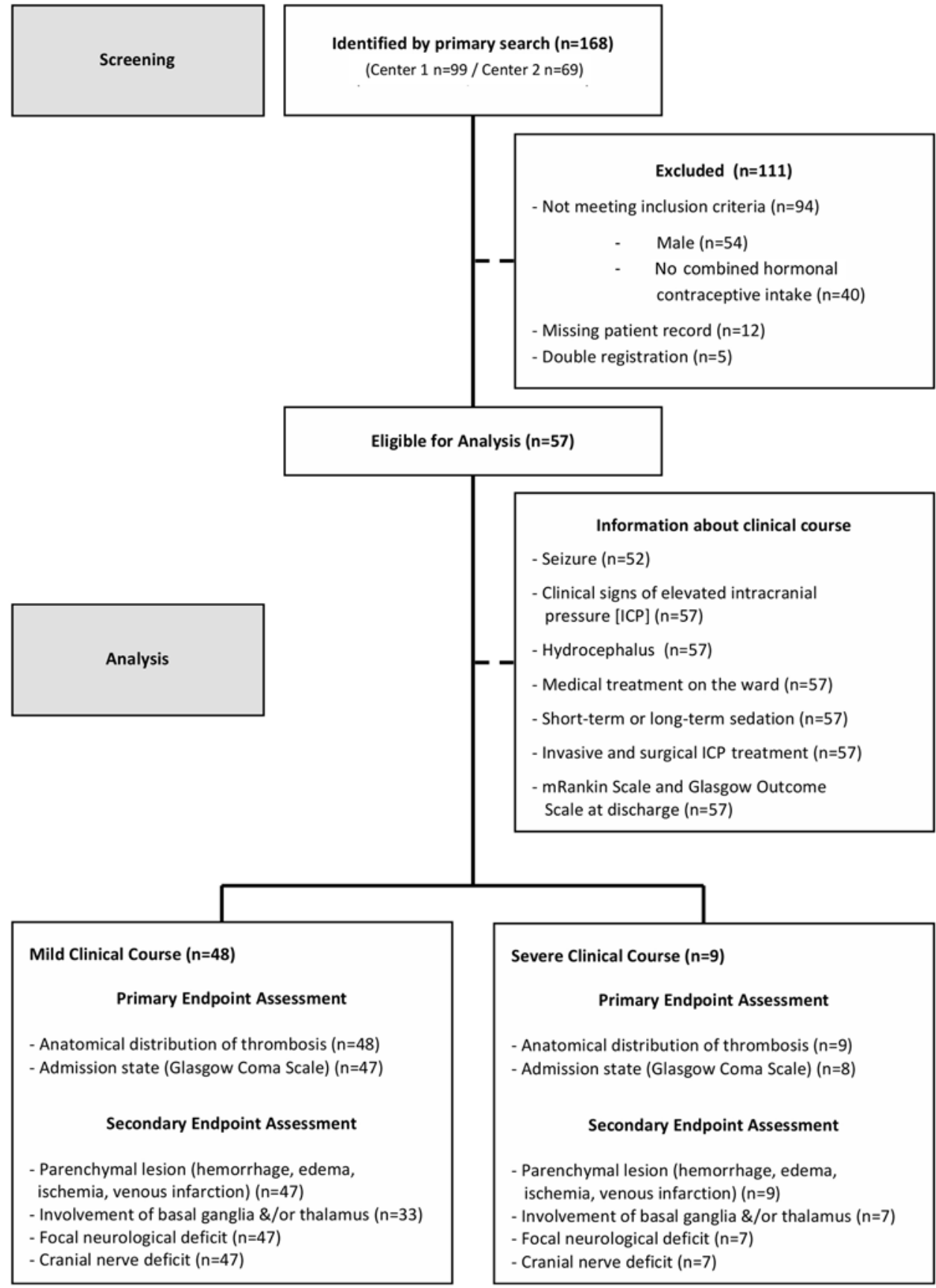

FIG. 1. Patient inclusion profile.

garding CHC intake. Thus 57 patients were eligible for analysis and were dichotomized.

\section{Patient Characteristics}

All included patients were women; their ages ranged from 16 to 49 years. Third-generation CHCs containing desogestrel or gestoden were the most commonly used type of CHC in both the mild and the severe clinical course groups. There was no significant difference be- tween the groups with respect to risk factor distribution (Table 1).

\section{Surgical and Medical Treatment for Elevated ICP (> $30 \mathrm{~mm} \mathrm{Hg}$ )}

Six of 57 patients $(10.5 \%)$ underwent surgery. Nine patients $(15.8 \%)$ underwent intensive care management, 3 of them with short-term sedation because of generalized epileptic seizures (these 3 patients were not in the severe 
clinical course group). Three patients displayed refractory ICP elevation leading to additional medical ICP treatment with associated infectious and hematological complications (Table 2).

\section{Outcome at Discharge}

The majority of patients $(87.7 \%)$ were discharged with an $\mathrm{mRS}$ score $\leq 2$ and a GOS score $\geq 4$. The in-hospital mortality rate was $1.8 \%(\mathrm{n}=1)$. Patients who underwent surgical ICP treatment were discharged with a favorable clinical outcome in $2(33.3 \%)$ and an unfavorable outcome in 4 cases $(66.7 \%)$ (Table 2).

\section{Predictive Radiological Characteristics at Admission \\ Extent of Thrombosis}

Compared to women with a mild clinical course, women who underwent invasive or surgical ICP treatment more frequently suffered from DCVT, including thrombosis of the great vein of Galen, bilateral thrombosis of the basal veins of Rosenthal, and bilateral thrombosis of the internal cerebral veins. However, in women with a severe course and unfavorable outcome, there were significantly fewer cases of thrombosis in the transverse sinus, without difference in laterality. Finally, there was no statistically significant between-groups difference in the incidence of DCVT (Tables 3 and 4).

\section{Hemorrhage, Edema, and Ischemia}

Women with a severe clinical course and surgical interventions more frequently presented with intraventricular as well parenchymal hemorrhage in the context of venous infarction as well as involvement of deep anatomical structures (Table 3).

\section{Hydrocephalus}

Women with CVT and hydrocephalus more frequently had DCVT (83.3\% vs 17.6\%), involvement of deep anatomical structures ( $83.3 \%$ vs $17.6 \%)$, and thrombosis of the straight sinus ( $83.3 \%$ vs $29.4 \%$ ), while thrombosis of the superior sagittal sinus was less likely to be present. Hydrocephalus was more common in surgically treated patients and those with an unfavorable outcome (Tables 3 and 4, Figs. 2 and 3).

\section{Clinical Presentation on Admission \\ Glasgow Coma Scale Scores}

Overall, 45 patients (78.9\%) presented with a GCS score of $13-15,2(3.5 \%)$ with a GCS score of 9-12, and $3(5.3 \%)$ with a GCS score of 3-8 on admission. The median GCS score on admission was significantly lower in women who underwent invasive or surgical ICP treatment and women with an unfavorable outcome (Table 5, Fig. 2).

\section{Clinical Signs of Increased ICP}

Clinical signs of increased ICP were more common among women with a severe clinical course (Table 5). A similar distribution was found among women who underwent invasive or surgical ICP treatment (Table 6, Fig. 2).
TABLE 1. Baseline characteristics of patients with CVT stratified by severity of clinical course

\begin{tabular}{lcc}
\hline \multicolumn{1}{c}{ Characteristic } & $\begin{array}{c}\text { Mild Clinical } \\
\text { Course } \\
(\mathrm{n}=48)\end{array}$ & $\begin{array}{c}\text { Severe Clinical } \\
\text { Course } \\
(\mathrm{n}=9)\end{array}$ \\
\hline Mean age in yrs (SD) & $31.5(9.7)$ & $30(7.3)$ \\
\hline CHCs, $\mathrm{n}(\%)$ & & \\
\hline 2nd gen (norgestrel, levonorgestrel) & $1(2.1)$ & $0(0.0)$ \\
\hline 3rd gen (desogestrel, gestoden) & $13(27.1)$ & $3(33.3)$ \\
\hline 4th gen (drospirenon) & $7(14.6)$ & $3(33.3)$ \\
\hline CHC containing cyproterone acetate & $8(16.7)$ & $0(0.0)$ \\
\hline Contraceptive patch (norelgestromin) & $2(4.2)$ & $0(0.0)$ \\
\hline Missing information on detailed CHC & $17(35.4)$ & $3(33.3)$ \\
substrate & & \\
\hline Additional risk factors, $\mathrm{n}(\%)$ & & \\
\hline Nicotine abuse & $11(22.9)$ & $1(11.1)$ \\
\hline Obesity (BMl $\left.\geq 30 \mathrm{~kg} / \mathrm{m}^{2}\right)$ & $8(16.7)$ & $3(33.3)$ \\
\hline Thrombophilia & $9(18.8)$ & $2(22.2)$ \\
\hline Dehydration & $4(8.3)$ & $2(22.2)$ \\
\hline Positive family history & $9(18.8)$ & $2(22.2)$ \\
\hline Steroids & $0(0.0)$ & $2(22.2)$ \\
\hline
\end{tabular}

$\mathrm{CHC}=$ combined hormonal contraceptive; gen = generation .

Mild clinical course: short sedation for seizure, no surgery, favorable outcome; severe clinical course: invasive and/or surgical ICP treatment, unfavorable outcome.

\section{Focal Neurological Deficits on Admission}

Neurological deficits were more frequent in women with a severe clinical course; in particular, quadriparesis on admission was more frequent in women with an unfavorable outcome. One patient $(2.1 \%)$ in the mild course group had quadriparesis because of bifrontal lesions. In women with an unfavorable outcome, cranial nerve deficits and impairment of eye movement at admission were more frequently documented (Table 7, Fig. 3).

\section{Discussion}

The use of combined hormonal contraceptives (CHCs) is a well-known risk factor for unprovoked CVT. ${ }^{1}$ The current study supports this, reporting a frequency of CHC usage in this group of patients who sustained CVT that is approximately twice as high as the application of hormonal contraceptives in the general Swiss population. ${ }^{6}$ Among the various types of $\mathrm{CHCs}$, third-generation $\mathrm{CHCs}$ containing desogestrel or gestoden reportedly confer the highest risk for CVT. ${ }^{1}$ In accordance with the findings of a prior study, cigarette smoking was approximately as common in our patient group as in the general Swiss population (Table 1). ${ }^{7,10,29}$

Aside from the clinical features, the current diagnosis of CVT is mainly based on imaging studies. ${ }^{28}$ The anatomical distribution of CVT within this study was similar to that reported in previous studies..$^{13}$ Parenchymal lesions such as hemorrhage, venous infarction, ischemia, or edema may facilitate the radiological diagnosis of CVT but are only present in $60 \%-70 \%$ of patients. ${ }^{13}$ Radiological signs 


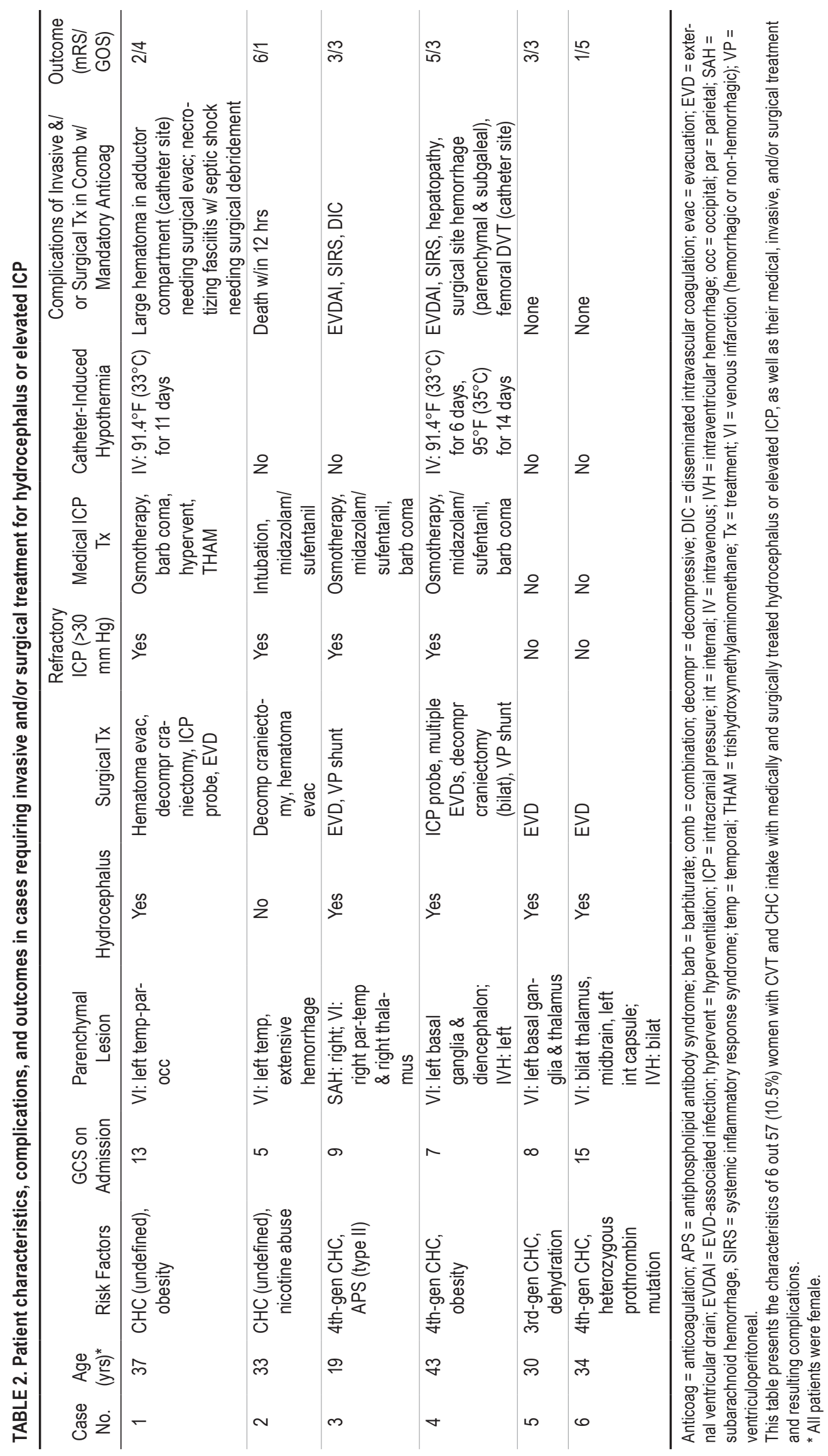


TABLE 3. Differences in anatomical distribution of CVT in women in need of invasive ICP management, EVD, or decompressive procedures compared to conservatively treated controls

\begin{tabular}{|c|c|c|c|}
\hline $\begin{array}{l}\text { Anatomical Extent of } \\
\text { CVT at Admission }\end{array}$ & $\begin{array}{l}\text { No ICP } \\
\quad \mathrm{Tx}(\mathrm{n} \\
=51 \\
[89.5 \%])\end{array}$ & $\begin{array}{l}\text { Invasive or } \\
\text { Surgical } \\
\text { ICP Tx }(n= \\
6[10.5 \%])\end{array}$ & $\begin{array}{c}p \\
\text { Value }\end{array}$ \\
\hline \multicolumn{4}{|l|}{ Affected venous location $(n=57)$} \\
\hline $\begin{array}{l}\text { Median no. of affected venous } \\
\text { locations per pt }\end{array}$ & 3 & 5 & $0.165 \dagger$ \\
\hline Sinus veins & $49(96.1)$ & $6(100)$ & - \\
\hline Transverse sinus & $46(90.2)$ & $4(66.7)$ & $0.153 \ddagger$ \\
\hline Left & $20(43.5)$ & $2(50.0)$ & - \\
\hline Right & $26(65.5)$ & $2(50.0)$ & - \\
\hline Sigmoid sinus & $39(76.5)$ & $4(66.7)$ & $0.629 \ddagger$ \\
\hline Superior sagittal & $25(43.9)$ & $1(16.7)$ & $0.205 \ddagger$ \\
\hline Inferior sagittal & $2(3.9)$ & $0(0.0)$ & - \\
\hline Straight sinus & $16(31.4)$ & $4(66.7)$ & $0.170 \ddagger$ \\
\hline Torcular herophili§ & $5(9.8)$ & $2(33.3)$ & $0.153 \ddagger$ \\
\hline Deep cerebral veins & $10(19.6)$ & $4(66.7)$ & $0.027 \ddagger$ \\
\hline Great vein of Galen & $8(15.7)$ & $4(66.7)$ & $0.015 \ddagger$ \\
\hline Basal vein of Rosenthal (bilat) & $1(2.0)$ & $2(33.3)$ & $0.027 \ddagger$ \\
\hline Internal cerebral vein (bilat) & $5(9.8)$ & $4(66.7)$ & $0.004 \ddagger$ \\
\hline Internal jugular vein & $23(45.1)$ & $2(33.3)$ & $0.686 \ddagger$ \\
\hline Cortical veins & 7 (13.7) & $0(0.0)$ & - \\
\hline \multicolumn{4}{|l|}{ Radiological variables } \\
\hline Missing radiological data & $1(2.0)$ & $0(0)$ & - \\
\hline Parenchymal lesions $(n=56)$ & $34(66.6)$ & $6(100)$ & $0.168 \ddagger$ \\
\hline Hemorrhage & $15(29.4)$ & $4(66.7)$ & $0.165 \ddagger$ \\
\hline $\mathrm{ICH}$ & $11(21.6)$ & $1(16.7)$ & - \\
\hline $\mathrm{SAH}$ & $4(7.8)$ & $1(16.7)$ & $0.445 \ddagger$ \\
\hline IVH & $0(0.0)$ & $2(33.3)$ & $0.010 \ddagger$ \\
\hline Edema & $13(25.5)$ & $2(33.3)$ & $0.654 \ddagger$ \\
\hline Perifocal & $10(19.6)$ & $2(33.3)$ & $0.599 \ddagger$ \\
\hline Generalized & $3(5.9)$ & $0(0.0)$ & - \\
\hline Ischemia & $6(11.8)$ & $1(16.7)$ & $0.569 \ddagger$ \\
\hline Venous infarction & $11(21.6)$ & $4(66.7)$ & $0.038 \ddagger$ \\
\hline Nonhemorrhagic & $6(11.8)$ & $1(16.7)$ & $0.569 \ddagger$ \\
\hline Hemorrhagic & $5(9.8)$ & $3(50)$ & $0.032 \ddagger$ \\
\hline $\begin{array}{l}\text { Involvement of basal } \\
\text { ganglia \&/or thalamus } \\
(n=42)\end{array}$ & $8(15.7)$ & $4(66.7)$ & $0.046 \ddagger$ \\
\hline Hydrocephalus $(n=57)$ & $1(2.0)$ & $5(83.3)$ & $<0.0001 \ddagger$ \\
\hline \multicolumn{4}{|c|}{$\begin{array}{l}\mathrm{Pt}=\text { patient. } \\
\text { Values represent number of cases (\%) unless otherwise indicated. Some } \\
\text { patients presented with more than } 1 \text { affected location or radiological lesion. } \\
\text { Statistical significance was set at } p \leq 0.05 \text {. } \\
\dagger \text { Mann-Whitney U-test. } \\
\ddagger \text { Fisher's exact chi-square test. } \\
\text { § Confluence of sinuses. }\end{array}$} \\
\hline
\end{tabular}

of hydrocephalus range from $4 \%-20 \%,{ }^{32,35}$ and appear to be associated with affected anatomical structures related to the foramina of Monro and the cerebral aqueduct.

The main cause of elevated ICP in acute CVT is trans-
TABLE 4. Differences in anatomical distribution of CVT in women with favorable outcomes compared to women with unfavorable outcome

\begin{tabular}{|c|c|c|c|}
\hline $\begin{array}{c}\text { Anatomical Extent of CVT at } \\
\text { Admission }\end{array}$ & $\begin{array}{c}\text { Favorable } \\
\text { Outcome } \\
(n=50 \\
[87.7 \%])\end{array}$ & $\begin{array}{l}\text { Unfavorable } \\
\text { Outcome }(\mathrm{n} \\
=7[12.3 \%])\end{array}$ & $\begin{array}{c}\mathrm{p} \\
\text { Value }\end{array}$ \\
\hline \multicolumn{4}{|l|}{ Affected venous locations $(n=57)$} \\
\hline $\begin{array}{l}\text { Median no. of affected venous } \\
\text { locations per pt }\end{array}$ & 3 & 4 & $0.826 \dagger$ \\
\hline Sinus veins & $48(96.0)$ & $7(100)$ & - \\
\hline Transverse sinus & $47(94.0)$ & $3(42.9)$ & $0.003 \ddagger$ \\
\hline Left & $20(42.6)$ & $0(0)$ & - \\
\hline Right & $27(57.4)$ & $3(100)$ & - \\
\hline Sigmoid sinus & $39(78.0)$ & $4(57.1)$ & $0.346 t$ \\
\hline Superior sagittal & $22(44.0)$ & $4(57.1)$ & $0.691 \ddagger$ \\
\hline Inferior sagittal & $2(4.0)$ & $0(0.0)$ & - \\
\hline Straight sinus & $16(32.0)$ & $4(57.1)$ & $0.226 \ddagger$ \\
\hline Torcular herophili & $5(10.0)$ & $2(28.6)$ & $0.202 \ddagger$ \\
\hline Deep cerebral veins & $11(22.0)$ & $3(42.9)$ & $0.346 \ddagger$ \\
\hline Great vein of Galen & $9(18.0)$ & $3(42.9)$ & $0.154 \ddagger$ \\
\hline Basal vein of Rosenthal (bilat) & $2(4.0)$ & $1(28.6)$ & $0.330 \ddagger$ \\
\hline Internal cerebral vein (bilat) & $5(10.0)$ & $3(42.9)$ & $0.050 \ddagger$ \\
\hline Internal jugular vein & $24(48.0)$ & $1(14.3)$ & $0.122 \ddagger$ \\
\hline Cortical veins & $7(14.0)$ & $0(0.0)$ & $0.579 \ddagger$ \\
\hline \multicolumn{4}{|l|}{ Radiological variables } \\
\hline Missing radiological data & $1(2.0)$ & $0(13)$ & \\
\hline Parenchymal lesions $(n=56)$ & $35(70.0)$ & $5(71.4)$ & - \\
\hline Hemorrhage & $16(23.0$ & $3(42.9)$ & $0.679 \ddagger$ \\
\hline $\mathrm{ICH}$ & $11(22.0)$ & $1(14.3)$ & - \\
\hline $\mathrm{SAH}$ & $4(8.0)$ & $1(14.3)$ & $0.501 \ddagger$ \\
\hline IVH & $0(0.0)$ & $1(14.3)$ & $0.125 \ddagger$ \\
\hline Edema & $13(26.0)$ & $2(28.6)$ & - \\
\hline Perifocal & $10(20.0)$ & $2(28.6)$ & $0.635 \ddagger$ \\
\hline Generalized & $3(6.0)$ & $0(0.0)$ & - \\
\hline Ischemia & $6(12.0)$ & $1(14.3)$ & - \\
\hline Venous infarction & $12(24.0)$ & $3(42.9)$ & $0.370 \ddagger$ \\
\hline Nonhemorrhagic & $6(12.0)$ & $1(14.3)$ & - \\
\hline Hemorrhagic & $6(12.0)$ & $2(28.6)$ & $0.259 \ddagger$ \\
\hline $\begin{array}{l}\text { Involvement of basal ganglia } \\
\quad \& / o r \text { thalamus }(n=40)\end{array}$ & $9(18.0)$ & $3(60)$ & $0.149 \ddagger$ \\
\hline Hydrocephalus $(n=57)$ & $3(6.0)$ & $3(42.9)$ & $0.020 \ddagger$ \\
\hline
\end{tabular}

Favorable outcome: $\mathrm{mRS}$ score $\leq 2$ or GOS score $\geq 4$; unfavorable outcome: $\mathrm{mRS}$ score $\geq 3$ or GOS score $\leq 3$. Some patients presented with more than 1 of the above listed locations or radiological lesions. Statistical significance was set at $p \leq 0.05$.

† Mann-Whitney U-test.

$\ddagger$ Fisher's exact chi-square test.

tentorial herniation due to unilateral focal mass effect or to diffuse parenchymal lesions with cerebral edema. ${ }^{8}$ According to the current guidelines of the European Academy of Neurology, published in 2017, there is still no more than scant evidence for the treatment of elevated ICP in 


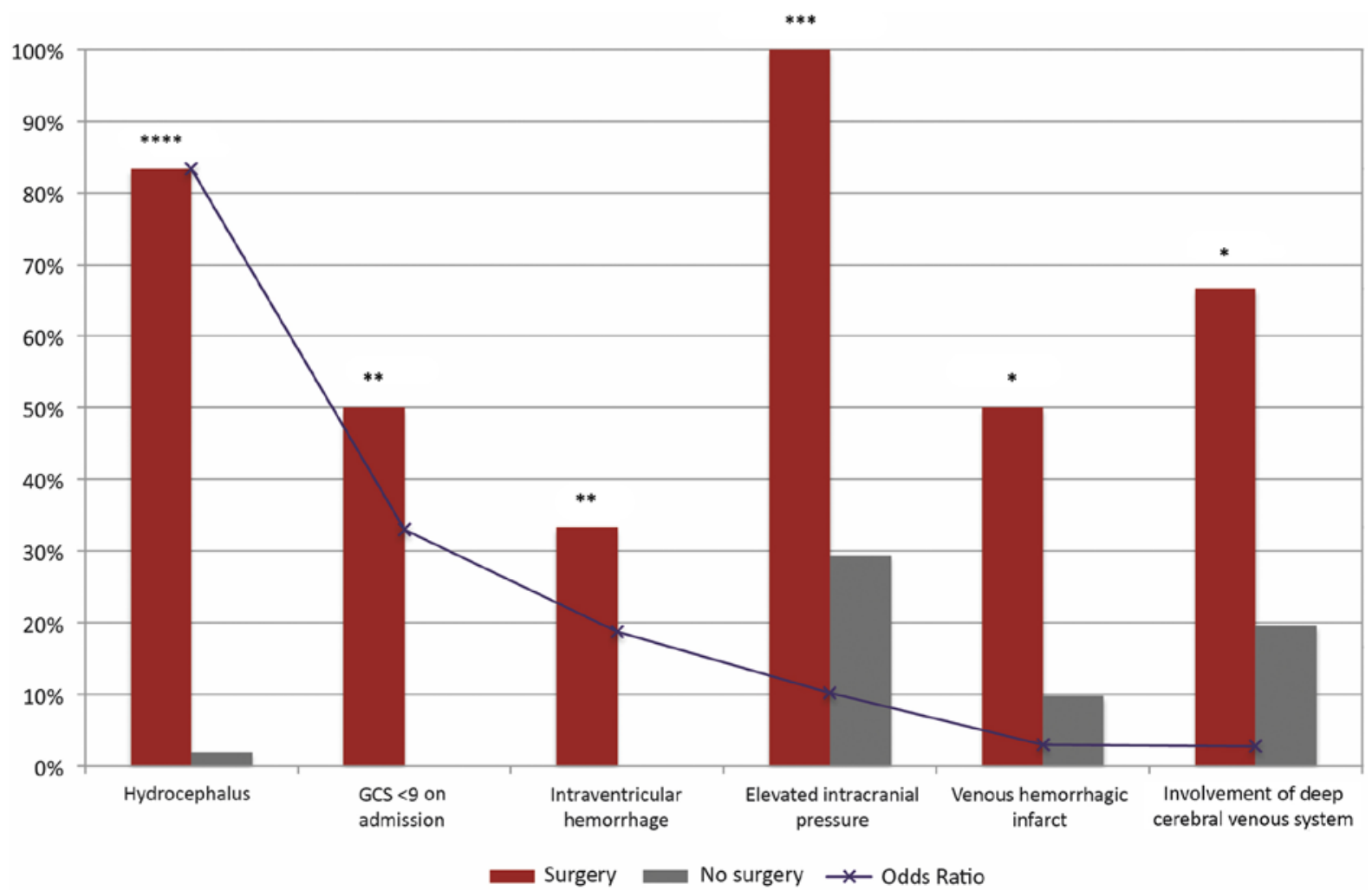

FIG. 2. Clinical and radiological factors associated with surgery for elevated ICP in CVT in women. Surgically treated patients $(5$ of $6[83.3 \%]$ ) were more likely to have hydrocephalus (OR 250.0, 95\% Cl 13.5-4636.9, $p<0.0001$ ) than patients in the conservatively treated group (1 of 51 [2.0\%]). Likewise, these patients (3 of 6 [50\%]) were more likely to present with coma $(\mathrm{GCS}$ score $<9)$ on admission (OR 99.0, 95\% Cl 4.2-2322.6, $p=0.004$ ) than conservatively treated patients $(0$ of $51[0.0 \%])$. The surgically treated group more commonly (OR $56.1,95 \% \mathrm{Cl} 2.3-1357.0, p=0.010)$ had intraventricular blood on a CT scan $(2$ of $6[33.3 \%$ ] than the conservatively treated patients $(0$ of $51[0.0 \%])$. Clinical signs of raised ICP were more common (OR $30.6,95 \% \mathrm{Cl} 1.6-577.5, p=$ $0.001)$ in the surgically treated group (6 of $6[100 \%]$ ) than in the conservatively treated group (14 of 51 [27.5\%]). Three of $6(50 \%)$ patients in the surgically treated group and 5 of $51(9.8 \%)$ in the conservative group had radiologically confirmed venous hemorrhagic infarction (OR 9.0, 95\% Cl 1.42-50.1, $p=0.032)$. Surgically treated patients more commonly $(\mathrm{OR} 8.2,95 \% \mathrm{Cl} 1.3-51.3, p=$ $0.027)$ had thrombosis of the deep venous system (4/6 [66.7\%] vs $10 / 51[19.6 \%])$. Statistically significant findings are marked as follows: $n s=$ not statistically significant $(p>0.05),{ }^{*} p \leq 0.05,{ }^{* *} p \leq 0.01,{ }^{* * *} p \leq 0.001,{ }^{* * * *} p \leq 0.0001$.

this rare disease..$^{11}$ No randomized controlled trials were found, but a small number of case series and nonrandomized controlled studies seem to show that decompressive surgery prevents death without causing excess severe disability. The available evidence led to a recommendation for surgical decompression in patients with severe CVT early in the time course of the disease..$^{14,26,31,34}$

Endovascular treatment options are increasingly advocated, particularly mechanical thrombectomy, with good recanalization rates. While partial or complete restoration of flow was reached in many cases with multimodal treatment, the mortality rate remained high. ${ }^{20}$ Cerebral edema and motor weakness were negative predictors for full recovery, while hormonal etiology correlated with favorable patient outcome. This is in accordance with the finding of our study that unfavorable outcomes are independent of treatment. The endovascular treatment complication rate is described in the literature as approximately $10 \%$, with a full recovery rate of $60 \% .{ }^{27}$ Therefore, endovascular intervention in this setting constitutes a valuable treatment option in selected cases. However, the optimal method to regain recanalization is yet to be determined. ${ }^{4,20,24,25,27}$
In some cases, progressive cerebral edema and expansion of hemorrhagic infarcts lead to refractory ICP after surgical decompression. In our case series, ICP monitoring and management were carried out in accordance with current guidelines to attain ICP levels below $20 \mathrm{~mm} \mathrm{Hg} .{ }^{9}$ However, in 3 refractory cases, the patients' ICP remained elevated above $30 \mathrm{~mm} \mathrm{Hg}$ even after decompressive surgery. Various nonsurgical treatment options have been assigned level IIB or level III recommendations in the traumatic brain injury management guidelines published by the Brain Trauma Foundation, including ventilation therapies, barbiturate coma, CSF drainage, and prophylactic hypothermia. ${ }^{9}$ This last option has been used to prevent and control neurological injuries in different pathologies, including traumatic brain injury and cardiac arrest. Case series describe the use of hypothermia, in combination with barbiturate coma, in patients who have suffered severe SAH and have intractable ICP elevation and/or refractory vasospasm..$^{16,19}$ The benefit of those modalities within the severe course of CVT remains unclear, especially because therapeutic anticoagulation is mandatory.,23 The present study revealed serious infectious and hematologi- 


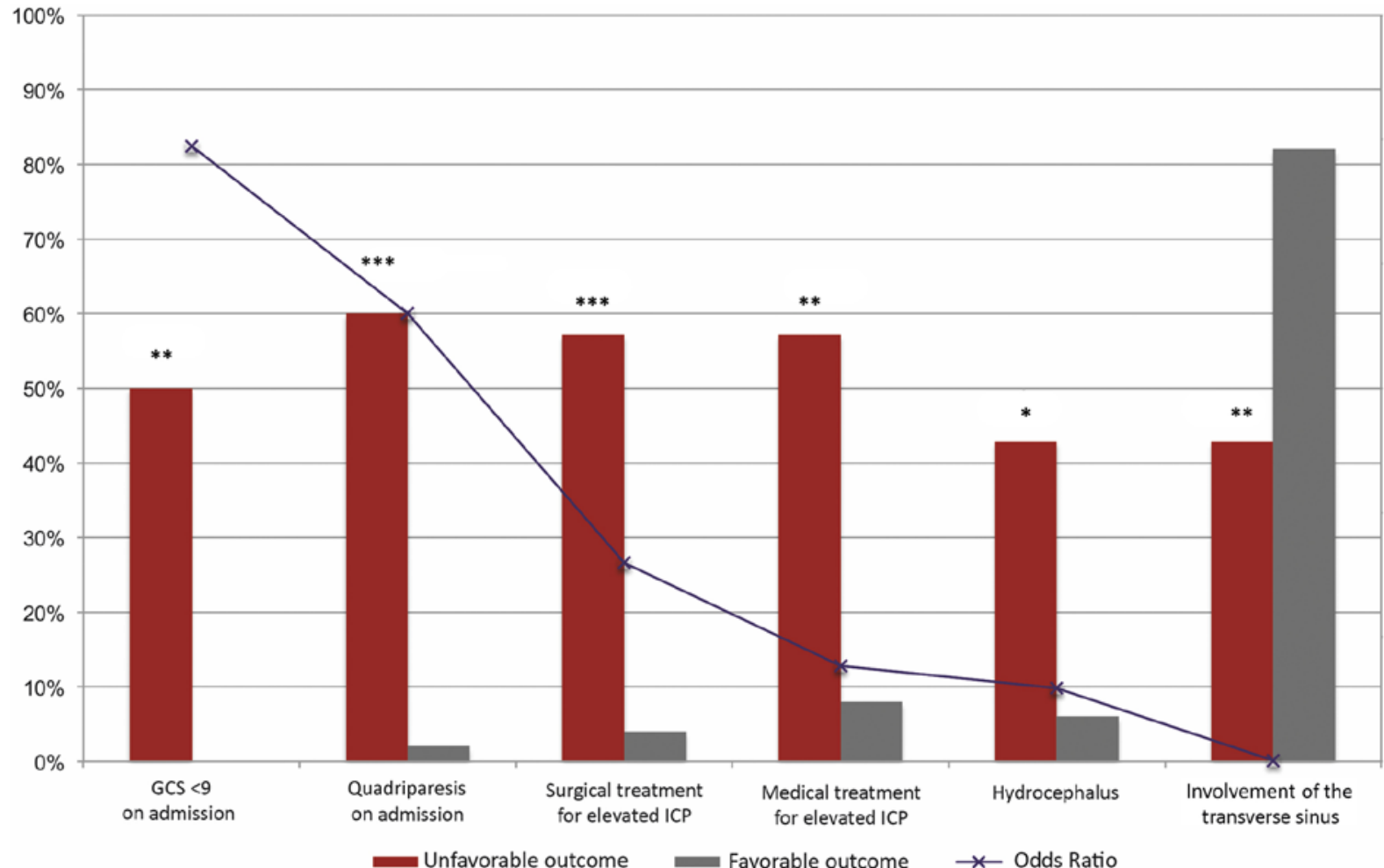

FIG. 3. Clinical and radiological factors associated with unfavorable outcome in women with CVT (unfavorable outcome defined as $\mathrm{mRS}$ score $\geq 3$ or GOS score $\leq 3$ ). Patients in the unfavorable outcome group ( $\mathrm{n}=1$ missing information) more commonly (OR $99,95 \% \mathrm{Cl} 4.2-2322.6, p=0.004)$ presented with coma (GCS score $<9$ ) on admission (3 of $6[50.0 \%]$ ) than those with a favorable outcome $(n=1$ missing information, 0 of $49[0.0 \%])$. Quadriparesis on admission was more common (OR $72,95 \% \mathrm{Cl} 5.0-1038, p$ $=0.001$ ) in the unfavorable outcome group (3 of $7[42.9 \%]$ ) than in the favorable outcome group (1 of 50 [2.0\%]). Four of 7 (57.1\%) patients in the unfavorable outcome group and 2 of $50(4.0 \%)$ in the favorable outcome group underwent surgical intervention for elevated ICP; such treatment was more common in the unfavorable outcome group (OR 32.0, 95\% Cl 4.1-251.0, $p=0.001$ ). Likewise, 4 of $7(57.1 \%)$ patients in the unfavorable outcome group and 4 of $50(8.0 \%)$ in the favorable outcome group underwent medical intensive care management of elevated ICP, which was more common in the unfavorable outcome group (OR $15.3,95 \% \mathrm{Cl}$ 2.5-93.9, $p=0.003$ ) than in the favorable outcome group. Hydrocephalus (either occlusive, malresorptive, or combined) was more common (OR 11.8, 95\% Cl 1.8-78.4, $p=0.020$ ) in the unfavorable outcome group (3 of $7[42.9 \%]$ ) than in the favorable outcome group (3 of 50 [6.0\%]). Finally, patients with an unfavorable outcome less commonly (OR $0.16,95 \% \mathrm{Cl} 0.03-0.87, p=0.003)$ had a thrombosis of the transverse sinus (3 of $7[42.9 \%]$ ) than those with a favorable outcome (47 of 50 [94.0\%]). Statistically significant findings are marked as follows: $n s=$ not statistically significant $(p>0.05),{ }^{*} p \leq 0.05,{ }^{* *} p \leq 0.01,{ }^{* * *} p \leq 0.001,{ }^{* * * *} p \leq 0.0001$.

cal complications (Table 2). These known side-effects of therapeutic hypothermia are attributable to impaired immune function, poor glycemic control, decreased gastrointestinal motility, and prolonged bleeding time as a result of reduction in the number and function of platelets. In combination with barbiturate coma, those side-effects might even be potentiated. ${ }^{21,22}$

Coma (GCS < 9) or a major neurological deficit (e.g., quadriparesis) on admission was found to predict an unfavorable outcome, while thrombosis of the transverse sinus was associated with a more favorable outcome, regardless of the side of the thrombosed sinus (Tables 4 and 7, Fig. 3). A simple explanation for this finding might be the moderate consequences of a unilateral thrombosed transverse sinus, compared to thrombosis of a "midline" venous structure without collateral or contralateral outflow. ${ }^{13}$

Two-thirds of the women who underwent neurosurgical procedures in our case series were discharged with an unfavorable outcome (Table 2). This might partly be explained by the greater severity of clinical course of CVT in these cases and predictors that are independent of the surgical intervention (Fig. 3). This poses the question whether an intervention alters the devastating natural course of severe CVT with elevated ICP. For patients with refractory ICP elevation after decompressive surgery, the addition of medical ICP treatment including barbiturate coma and induced hypothermia might be last-resort options with the potential for high morbidity in combination with mandatory anticoagulation regimes.

Our study has limitations. Because of the small size of this retrospective study, our findings should be interpreted with caution. Only univariate analysis was indicated, and the positive findings are not necessarily robust. Furthermore, we relied on the GSC score that was documented on admission and not during hospitalization. Therefore, a statement regarding clinical decline and its time course is not possible based on the current data. Nevertheless, our findings are in accordance with those of previous studies and were made in a homogeneous population of women with $\mathrm{CHC}$ intake without other morbidities likely to cause 
TABLE 5. Clinical presentation at admission stratified by severity of clinical course

\begin{tabular}{lccc}
\hline \multicolumn{1}{c}{ Characteristic } & $\begin{array}{c}\text { Mild } \\
\text { Clinical } \\
\text { Course }\end{array}$ & $\begin{array}{c}\text { Severe } \\
\text { Clinical } \\
\text { Course }\end{array}$ & $\begin{array}{c}p \\
\text { Value }\end{array}$ \\
\hline No. of pts (\%) & $48(84.2)$ & $9(15.8)$ & \\
\hline Missing data for GCS score & $1(2.1)$ & $1(11.1)$ & \\
\hline Missing data for focal neurology & $1(2.1)$ & $2(22.2)$ & \\
\hline Missing data for seizures & $1(2.1)$ & $4(44.4)$ & \\
\hline GCS score & \multicolumn{3}{|c}{} \\
\hline$\quad$ Median & 15 & 9 & $0.004 \dagger$ \\
\hline$\quad$ SD & 1.0 & 3.5 & \\
\hline Increased ICP§ & $14(29.2)$ & $7(77.8)$ & $0.009 \ddagger$ \\
\hline Seizures & $23(48.9)$ & $1(20)$ & $0.356 \ddagger$ \\
\hline
\end{tabular}

Data are number of patients (\%) unless otherwise indicated. Statistical significance was set at $p \leq 0.05$.

$\dagger$ Mann-Whitney U-test.

$\ddagger$ Fisher's exact chi-square test.

$\S$ Defined as $>15 \mathrm{~mm} \mathrm{Hg}$ in lumbar puncture or clinical signs (e.g., headaches, nausea, vomiting, altered consciousness, papilledema).

TABLE 6. Clinical presentation at admission stratified by need for invasive ICP management

\begin{tabular}{lccc}
\hline \multicolumn{1}{c}{ Characteristic } & $\begin{array}{c}\text { Invasive or } \\
\text { Surgical } \\
\text { No ICP } \\
\text { ICP }\end{array}$ & $\begin{array}{c}\text { P } \\
\text { Treatment }\end{array}$ & $\begin{array}{c}\text { Treatment } \\
\text { Value }\end{array}$ \\
\hline No. of pts (\%) & $51(89.5)$ & $6(10.5)$ & \\
\hline GCS score & & & \\
\hline Median & 15 & 9 & $0.004 \dagger$ \\
\hline SD & 1.2 & 3.5 & \\
\hline Increased ICP§ & $14(27.5)$ & $6(100)$ & $0.001 \ddagger$ \\
\hline Seizures & $24(47.0)$ & $0(16.7)$ & $0.120 \ddagger$ \\
\hline Focal neuro deficit of cerebral origin & $25(49.0)$ & $5(83.3)$ & $0.059 \ddagger$ \\
\hline Quadriparesis & $1(2.0)$ & $1(16.7)$ & $0.178 \ddagger$ \\
\hline Hemisyndrome & $10(19.6)$ & $3(50)$ & $0.084 \ddagger$ \\
\hline Isolated focal deficit (incl aphasia) & $14(27.4)$ & $1(16.7)$ & - \\
\hline CN deficit & $11(21.6)$ & $3(50.0)$ & $0.103 \ddagger$ \\
\hline Eye movement (III/IV/VI) & $5(9.8)$ & $3(50.0)$ & $0.019 \ddagger$ \\
\hline Upper CNs (V, VII, VIII) & $8(15.7)$ & $0(0.0)$ & - \\
\hline Lower CNs (IX, X, XI) & $2(4.0)$ & $0(0.0)$ & - \\
\hline
\end{tabular}

$\mathrm{CN}=$ cranial nerve; incl $=$ including; neuro $=$ neurological.

Data are number of patients (\%) unless otherwise indicated. Some patients presented with more than 1 deficit. Statistical significance was set at $p \leq 0.05$. $\dagger$ Mann-Whitney U-test.

$\ddagger$ Fisher's exact chi-square test.

$\S$ Defined as $>15 \mathrm{~mm} \mathrm{Hg}$ in lumbar puncture or clinical signs (e.g., headaches, nausea, vomiting, altered consciousness, papilledema).

CVT. We have tentatively identified clinical and radiological predictive factors for a severe clinical course. Prospective studies in large cohorts are needed to validate the predictive value of these factors for the invasive and surgical treatment of elevated ICP.
TABLE 7. Clinical presentation at admission stratified by outcome

\begin{tabular}{lccc}
\hline \multicolumn{1}{c}{ Characteristic } & $\begin{array}{c}\text { Favorable } \\
\text { Outcome }\end{array}$ & $\begin{array}{c}\text { Unfavorable } \\
\text { Outcome }\end{array}$ & $\begin{array}{c}\mathrm{p} \\
\text { Value }\end{array}$ \\
\hline No. of pts, n (\%) & $50(87.7)$ & $7(12.3)$ & \\
\hline GCS score & & & \\
\hline Median & 15 & 9 & $0.002 \dagger$ \\
\hline SD & 1.0 & 3.1 & \\
\hline Increased ICP & $16(32.0)$ & $5(71.4)$ & $0.087 \ddagger$ \\
\hline Seizures & $23(46.0)$ & $1(14.3)$ & $0.367 \ddagger$ \\
\hline Focal neuro deficit of cerebral origin & $23(46.0)$ & $5(71.4)$ & $0.052 \ddagger$ \\
\hline Quadriparesis & $1(2.0)$ & $3(42.9)$ & $0.001 \ddagger$ \\
\hline Hemisyndrome & $11(22.0)$ & $2(28.6)$ & $0.584 \ddagger$ \\
\hline Isolated focal deficit (incl & $15(30.0)$ & $0(0.0)$ & $0.306 \ddagger$ \\
$\quad$ aphasia) & & & \\
\hline CN deficit & $10(20.0)$ & $4(57.1)$ & $0.013 \ddagger$ \\
\hline Eye movement (III/IV/VI) & $5(10.0)$ & $3(42.9)$ & $0.019 \ddagger$ \\
\hline Upper CNs (V, VII, VIII) & $7(14.0)$ & $1(14.3)$ & $0.567 \ddagger$ \\
\hline Lower CNs (IX, X, XI) & $2(4.0)$ & $0(0.0)$ & - \\
\hline
\end{tabular}

Favorable outcome: $m R S$ score $\leq 2$ or GOS score $\geq 4$; unfavorable outcome: $m R S$ score $\geq 3$ or GOS score $\leq 3$. Data are number of patients (\%) unless otherwise indicated. Some patients presented with more than 1 deficit. Statistical significance was set at $p \leq 0.05$.

† Mann-Whitney U-test.

$\ddagger$ Fisher's exact chi-square test.

$\S$ Defined as $>15 \mathrm{~mm} \mathrm{Hg}$ in lumbar puncture or clinical signs (e.g., headaches, nausea, vomiting, altered consciousness, papilledema).

\section{Conclusions}

The rare case of CVT associated with $\mathrm{CHC}$ use that may require neurosurgical procedures and other medical therapies to control elevated ICP remains a serious complication. Clinical and radiological factors on admission may partly predict such invasive interventions. The addition of known medical strategies for refractory ICP might lead to a higher rate of infectious, thromboembolic, and hemorrhagic complications and higher morbidity. The significance of these factors needs to be further investigated in prospective multicenter studies.

\section{Acknowledgments}

We thank Andrea Roethlisberger for orthography and language revision and Selina Ackermann for manuscript preparation and submission support.

\section{References}

1. Amoozegar F, Ronksley PE, Sauve R, Menon BK: Hormonal contraceptives and cerebral venous thrombosis risk: a systematic review and meta-analysis. Front Neurol 6:7, 2015

2. Andresen M, Gazmuri JT, Marín A, Regueira T, Rovegno M: Therapeutic hypothermia for acute brain injuries. Scand J Trauma Resusc Emerg Med 23:42, 2015

3. Bezemer ID, van der Meer FJ, Eikenboom JC, Rosendaal FR, Doggen CJ: The value of family history as a risk indicator for venous thrombosis. Arch Intern Med 169:610-615, 2009

4. Bhogal P, AlMatter M, Aguilar M, Nakagawa I, Ganslandt O, Bäzner H, et al: Cerebral venous sinus thrombosis: endovascular treatment with rheolysis and aspiration thrombectomy. Clin Neuroradiol 27:235-240, 2017 
5. Bousser MG, Ferro JM: Cerebral venous thrombosis: an update. Lancet Neurol 6:162-170, 2007

6. Bundesamt für Statistik BFS: Anwendung von Verhütungsmethoden, 2012. Schweizerische Gesundheitsbefragung (SGB). Neuchatel, Switzerland: Bundesamt für Statistik BFS, August 9, 2016, vol 2017 (Ger)

7. Bundesamt für Statistik BFS: Gesundheit: Panorama. Neuchatel, Switzerland: Bundesamt für Statistik BFS, September 16, 2014, vol 2017 (Ger)

8. Canhão P, Ferro JM, Lindgren AG, Bousser MG, Stam J, Barinagarrementeria F: Causes and predictors of death in cerebral venous thrombosis. Stroke 36:1720-1725, 2005

9. Carney N, Totten AM, O'Reilly C, Ullman JS, Hawryluk GW, Bell MJ, et al: Guidelines for the Management of Severe Traumatic Brain Injury, Fourth Edition. Neurosurgery 80:6-15, 2017

10. Ciccone A, Gatti A, Melis M, Cossu G, Boncoraglio G, Carriero $\mathrm{MR}$, et al: Cigarette smoking and risk of cerebral sinus thrombosis in oral contraceptive users: a case-control study. Neurol Sci 26:319-323, 2005

11. Einhäupl K, Stam J, Bousser MG, De Bruijn SF, Ferro JM, Martinelli I, et al: EFNS guideline on the treatment of cerebral venous and sinus thrombosis in adult patients. Eur J Neurol 17:1229-1235, 2010

12. Farrell B, Godwin J, Richards S, Warlow C: The United Kingdom transient ischaemic attack (UK-TIA) aspirin trial: final results. J Neurol Neurosurg Psychiatry 54:1044-1054, 1991

13. Ferro JM, Canhão P, Stam J, Bousser MG, Barinagarrementeria F: Prognosis of cerebral vein and dural sinus thrombosis: results of the International Study on Cerebral Vein and Dural Sinus Thrombosis (ISCVT). Stroke 35:664-670, 2004

14. Ferro JM, Crassard I, Coutinho JM, Canhão P, Barinagarrementeria F, Cucchiara B, et al: Decompressive surgery in cerebrovenous thrombosis: a multicenter registry and a systematic review of individual patient data. Stroke 42:2825-2831, 2011

15. Galarza M, Gazzeri R: Cerebral venous sinus thrombosis associated with oral contraceptives: the case for neurosurgery. Neurosurg Focus 27(5):E5, 2009

16. Gasser S, Khan N, Yonekawa Y, Imhof HG, Keller E: Longterm hypothermia in patients with severe brain edema after poor-grade subarachnoid hemorrhage: feasibility and intensive care complications. J Neurosurg Anesthesiol 15:240248,2003

17. Jennett B, Snoek J, Bond MR, Brooks N: Disability after severe head injury: observations on the use of the Glasgow Outcome Scale. J Neurol Neurosurg Psychiatry 44:285-293, 1981

18. Keller E, Pangalu A, Fandino J, Könü D, Yonekawa Y: Decompressive craniectomy in severe cerebral venous and dural sinus thrombosis. Acta Neurochir Suppl 94:177-183, 2005

19. Lerch C, Yonekawa Y, Muroi C, Bjeljac M, Keller E: Specialized neurocritical care, severity grade, and outcome of patients with aneurysmal subarachnoid hemorrhage. Neurocrit Care 5:85-92, 2006

20. Mokin M, Lopes DK, Binning MJ, Veznedaroglu E, Liebman $\mathrm{KM}$, Arthur AS, et al: Endovascular treatment of cerebral venous thrombosis: Contemporary multicenter experience. Interv Neuroradiol 21:520-526, 2015

21. Muroi C, Frei K, El Beltagy M, Cesnulis E, Yonekawa Y, Keller E: Combined therapeutic hypothermia and barbiturate coma reduces interleukin-6 in the cerebrospinal fluid after aneurysmal subarachnoid hemorrhage. J Neurosurg Anesthesiol 20:193-198, 2008

22. Polderman KH: Application of therapeutic hypothermia in the intensive care unit. Opportunities and pitfalls of a promising treatment modality - part 2: Practical aspects and side effects. Intensive Care Med 30:757-769, 2004

23. Polderman KH: Induced hypothermia and fever control for prevention and treatment of neurological injuries. Lancet 371:1955-1969, 2008
24. Poulsen FR, Høgedal L, Stilling MV, Birkeland PF, Schultz MK, Rasmussen JN: Good clinical outcome after combined endovascular and neurosurgical treatment of cerebral venous sinus thrombosis. Dan Med J 60: A4724, 2013

25. Qureshi AI, Grigoryan M, Saleem MA, Aytac E, Wallery SS, Rodriguez GJ, et al: Prolonged microcatheter-based local thrombolytic infusion as a salvage treatment after failed endovascular treatment for cerebral venous thrombosis: a multicenter experience. Neurocrit Care [epub ahead of print], 2018

26. Raza E, Shamim MS, Wadiwala MF, Ahmed B, Kamal AK: Decompressive surgery for malignant cerebral venous sinus thrombosis: a retrospective case series from Pakistan and comparative literature review. J Stroke Cerebrovasc Dis 23:e13-e22, 2014

27. Salottolo K, Wagner J, Frei DF, Loy D, Bellon RJ, McCarthy $\mathrm{K}$, et al: Epidemiology, endovascular treatment, and prognosis of cerebral venous thrombosis: US center study of 152 patients. J Am Heart Assoc 6:e005480, 2017

28. Saposnik G, Barinagarrementeria F, Brown RD Jr, Bushnell $\mathrm{CD}$, Cucchiara B, Cushman M, et al: Diagnosis and management of cerebral venous thrombosis: a statement for healthcare professionals from the American Heart Association/ American Stroke Association. Stroke 42:1158-1192, 2011

29. Suchon P, Al Frouh F, Henneuse A, Ibrahim M, Brunet D, Barthet MC, et al: Risk factors for venous thromboembolism in women under combined oral contraceptive. The PILl Genetic RIsk Monitoring (PILGRIM) Study. Thromb Haemost 115:135-142, 2016

30. Teasdale G, Jennett B: Assessment of coma and impaired consciousness. A practical scale. Lancet 2:81-84, 1974

31. Théaudin M, Crassard I, Bresson D, Saliou G, Favrole P, Vahedi K, et al: Should decompressive surgery be performed in malignant cerebral venous thrombosis?: a series of 12 patients. Stroke 41:727-731, 2010

32. Wasay M, Bakshi R, Bobustuc G, Kojan S, Sheikh Z, Dai A, et al: Cerebral venous thrombosis: analysis of a multicenter cohort from the United States. J Stroke Cerebrovasc Dis 17:49-54, 2008

33. Zuurbier SM, Arnold M, Middeldorp S, Broeg-Morvay A, Silvis SM, Heldner MR, et al: Risk of cerebral venous thrombosis in obese women. JAMA Neurol 73:579-584, 2016

34. Zuurbier SM, Coutinho JM, Majoie CB, Coert BA, van den Munckhof P, Stam J: Decompressive hemicraniectomy in severe cerebral venous thrombosis: a prospective case series. J Neurol 259:1099-1105, 2012

35. Zuurbier SM, van den Berg R, Troost D, Majoie CB, Stam J, Coutinho JM: Hydrocephalus in cerebral venous thrombosis. J Neurol 262:931-937, 2015

\section{Disclosures}

This study was supported by funds from the Department of Neurosurgery, University Hospital of Basel. The Department of Clinical Pharmacology, University Hospital of Zürich, provided support for the local data collection and ethical approval.

\section{Author Contributions}

Conception and design: Roethlisberger, Corti, Bozinov, Mariani. Acquisition of data: Roethlisberger, Gut, Maldaner, Croci. Analysis and interpretation of data: all authors. Drafting the article: Roethlisberger, Gut, Boss, Taub, Burkhardt. Critically revising the article: all authors. Reviewed submitted version of manuscript: all authors. Approved the final version of the manuscript on behalf of all authors: Roethlisberger. Statistical analysis: Roethlisberger. Administrative/technical/material support: Roethlisberger, Gut. Study supervision: Roethlisberger, Mariani.

\section{Correspondence}

Michel Roethlisberger: University Hospital of Basel, Switzerland. michel.roethlisberger@usb.ch. 